\title{
Bending Analysis of a Cantilever Nanobeam With End Forces by Laplace Transform
}

\author{
Mustafa Özgür Yayli ${ }^{a}$,Suheyla Yerel Kandemir ${ }^{b}$ \\ ${ }^{a}$ Uludağ University Engineering Faculty Department of Civil Engineering, Bursa,Turkey \\ ${ }^{a}$ Bilecik SE University Engineering Faculty Department of Civil Engineering, Bilecik,Turkey \\ *E-mail address: ozguryayli@uludag.edu.tr
}

Received date: May 2017

Accepted date: June 2017

\begin{abstract}
In this study, the static behavior of nanobeams subjected to end concentrated loads is theoretically investigated in the Laplace domain. A closed form of solution for the title problem is presented using Euler-Bernoulli beam theory. Nonlocal elasticity theory proposed by Eringen is used to represent small scale effect. A system of differential equations containing a small scale parameter is derived for nanobeams. Laplace transformation is applied to this system of differential equations containing a small scale parameter. The exact static response of the nanobeam with end concentrated loads is obtained by applying inverse Laplace transform. The calculate results are plotted in a series of figures for various combinations of concentrated loads.
\end{abstract}

Keywords: Nonlocal elasticity theory, nanobeam, Laplace transform, static response.

\section{Introduction}

Single walled carbon nanotubes (nanobeams) are non-classical nanomaterials of current interest in several applicative sectors, such as electronics, medicine and engineering. They have superior mechanical and electrical properties and their potential applications in optics, electronics and other fields of nanotechnology. Classical continuum theory is size-free theory and this theory lacks the accountability of the size effects arising from the small-size. There have been different non classical continuum theories used to overcome small size effects. Integral type, differential equation type or gradient nonlocal elasticity type models abandon the classical elasticity assumption of local model, and stated that stress depends not only on the strain at that point.

Eringen [1] proposed the new higher order continuum theory known as "nonlocal elasticity theory" in 1970s. In this theory small size effect can be considered in the constitutive equations simply as a material scale parameter. Nonlocal elasticity theory based nano sized structures are new materials (nanomaterials) which are designed to achieve a higher performance in physical and mechanical properties. The nonlocal continuum theory has been widely applied to many mechanical problems of a wide range of interest, including the bending, buckling, and vibration of beam-like structures [2-4] and plate-like structures [5-7] and elements in nano and micro sized structures. Many research papers correlated to nonlocal continuum theories have been addressed the small scale effects in nanostructures and apply these higher order elasticity theories to determine the mechanical behavior of nanostructures, see Refs. [8-25]. 
In this work, a Laplace transformation is introduced for the bending analysis of the cantilever nanobeams with end concentrated loads (initial value problems). A systems of differential equations is derived with initial and boundary conditions. Laplace transformation is applied to this systems of differential equations containing nonlocal elasticity parameter with known initial conditions. The closed form of solutions of the nanobeam with end concentrated loads is derived by applying inverse Laplace transform.

\section{Formulation of the problem}

The constitutive relation, the equations of equilibrium and geometrical compatibility condition of a nanobeam in the two dimensional plane are [26].

$$
\begin{gathered}
\frac{d w}{d x}=\varphi, \\
\frac{d \varphi}{d x}=\frac{-M}{E I}, \\
\frac{d M}{d x}=P_{1} \varphi+T, \\
\frac{d T}{d z}=0,
\end{gathered}
$$

where $\mathrm{M}$ and $\mathrm{T}$ are the bending moment and the shear force, $\mathrm{w}$ and $\varphi$ are the lateral displacement and the slope of the beam. On the other hand, Eq. (2) takes a different form in nonlocal elasticity [27].

$$
M-\left(e_{0} a\right)^{2} \frac{d^{2} M}{d x^{2}}=-E I \frac{d^{2} w}{d x^{2}},
$$

where $\mathrm{a}$ is the internal characteristic length, is a constant $\left(e_{0}=0.39, a=4 \times 10^{-8} \mathrm{~cm}\right)$. Using Eq. (2), above relation takes the following form

$$
\frac{M}{E I}=\left(1-\frac{\left(e_{0} a\right)^{2} P_{1}}{E I}\right) \frac{d \varphi}{d x}
$$

then according to nonlocal elasticity theory, the system of differential equations is given by [26].

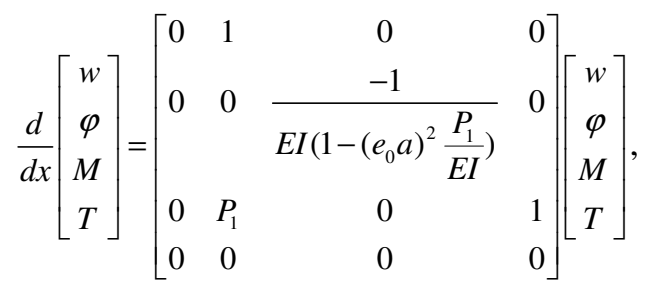


where $E I$ is the flexural rigidity of the nanobeam, $E$ is Young's modulus, $I$ is the moment of inertia of the cross-sectional area $A, \mathrm{P}_{1}$ the axial concentrated force, $\mathrm{P}_{2}$ the lateral concentrated force, a the internal characteristic length and $\mathrm{e}_{0}$ is a constant. The initial conditions can be calculated as follows;

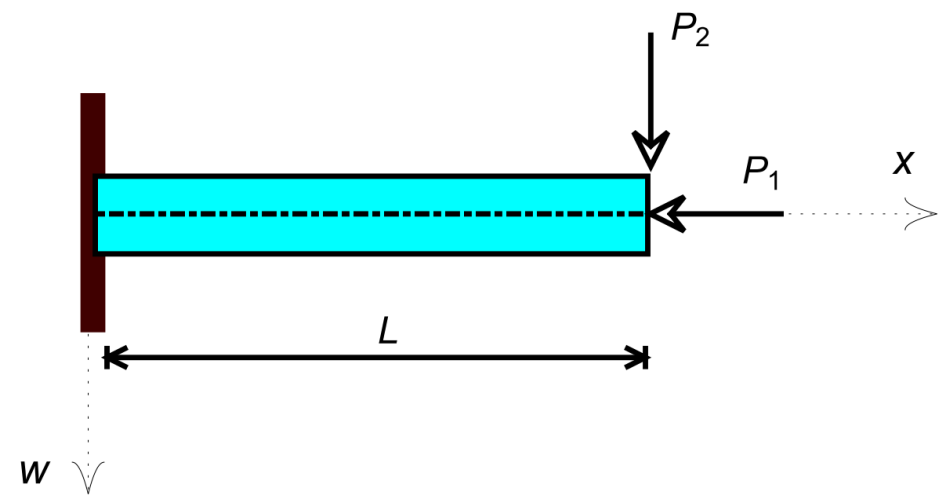

Fig. 1. A cantilever nanobeam with end concentrated forces

$$
\begin{gathered}
w(0)=0, \\
\varphi(0)=0, \\
M(0)=-P_{2} L, \\
T(0)=P_{2} .
\end{gathered}
$$

The following systems of differential equations can be derived from the Eq. (7):

$$
\begin{gathered}
\frac{d w}{d x}=\varphi, \\
\frac{d \varphi}{d x}=\frac{-1}{E I\left(1-\left(e_{0} a\right)^{2} \frac{P_{1}}{E I}\right)} M, \\
\frac{d M}{d x}=P_{1} \varphi+T, \\
\frac{d T}{d z}=0 .
\end{gathered}
$$

\section{Closed form of solutions}

By applying Laplace transform to these equations:

$$
s w(S)-w(0)=\varphi(S)
$$




$$
\begin{gathered}
s \varphi(S)-\varphi(0)=\frac{-1}{E I\left(1-\left(e_{0} a\right)^{2} \frac{P_{1}}{E I}\right)} M(S), \\
s M(S)+M(0)=P_{1} \varphi(S)+T(S), \\
s T(S)-T(0)=0,
\end{gathered}
$$

then using the initial conditions given in Eqs. (8-11), following equations are derived in Laplace domain:

$$
\begin{gathered}
w(S)=-\frac{-P_{2}+L P_{2} s}{s^{2}\left(-P_{1}-E I s^{2}+P_{1} s^{2}\left(e_{0} a\right)^{2}\right)}, \\
\varphi(S)=-\frac{-P_{2}-L P_{2} s}{s^{2}\left(P_{1}+E I s^{2}-P_{1} s^{2}\left(e_{0} a\right)^{2}\right)}, \\
M(S)=-\frac{E I P_{2}-E I L P_{2} s-P_{1} P_{2}\left(e_{0} a\right)^{2}+L P_{1} P_{2} s\left(e_{0} a\right)^{2}}{\left.-P_{1}-E I s^{2}+P_{1} s^{2}\left(e_{0} a\right)^{2}\right)}, \\
T(S)=\frac{P_{2}}{s} .
\end{gathered}
$$

Inverse Laplace transforms of above equations give the closed form of solutions:

$$
\begin{gathered}
w[x]=\frac{P_{2}(L-x)}{P_{1}}-\frac{L P_{2} \cosh \left[\frac{\sqrt{P_{1}} x}{\sqrt{-E I+P_{1}\left(e_{o} a\right)^{2}}}\right]}{P_{1}}+\frac{P_{2} \sqrt{-E I+P_{1}\left(e_{o} a\right)^{2}} \sinh \left[\frac{\sqrt{P_{1}} x}{\sqrt{-E I+P_{1}\left(e_{o} a\right)^{2}}}\right]}{P_{1}^{\frac{3}{2}}}, \\
\left.\varphi[x]=\frac{P_{2}\left(-1+\cosh \left[\frac{\sqrt{P_{1}} x}{\sqrt{-E I+P_{1}\left(e_{o} a\right)^{2}}}\right]-\frac{L \sqrt{P_{1}} \sinh \left[\frac{\sqrt{P_{1}} x}{\sqrt{-E I+P_{1}\left(e_{o} a\right)^{2}}}\right]}{\sqrt{-E I+P_{1}\left(e_{o} a\right)^{2}}}\right)}{P_{1}}, \frac{\sqrt{P_{1}} x}{\sqrt{P_{1}}}\right] \\
M[x]=L P_{2} \cosh \left[\frac{P_{2} \sqrt{-E I+P_{1}\left(e_{o} a\right)^{2}} \sinh \left[\frac{P_{1}\left(e_{o} a\right)^{2}}{\sqrt{-E I+P_{1}\left(e_{o} a\right)^{2}}}\right]+\frac{T[x]=P_{2} .}{}}{T},\right.
\end{gathered}
$$

\section{Numerical results}

To evaluate the significance of end loads on the static analysis of nonlocal beams, this section considers a nano-sized beam with the end concentrated forces. Here we assume $\mathrm{E}^{*} \mathrm{I}=1 \mathrm{nN} \cdot \mathrm{m}^{2}, \mathrm{e}_{0} \mathrm{a}=1$ $\mathrm{nm}$. In order to investigate the significances of end axial concentrated forces on the mechanical behaviors of the nanobeam, its bending behaviors are compared. The significances of the end axial 
and lateral forces on the linear bending deflection of the cantilever nanobeam are investigated by using the nonlocal elastic Euler-Bernoulli beam model. Figs. 2 and 3 reveal the effect of the end concentrated forces on the deflection with end lateral force and the deflection with end axial force of a cantilever nanobeam, respectively.

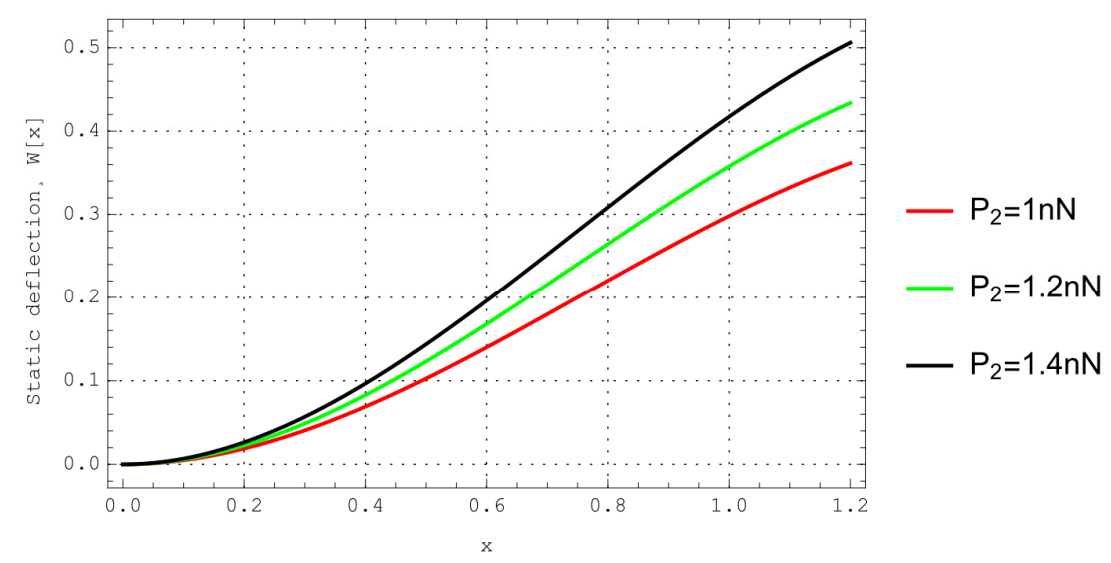

Fig. 2. Static deflection for different concentrated forces $\left(\mathrm{P}_{1}=1.2 \mathrm{nN}\right)$.

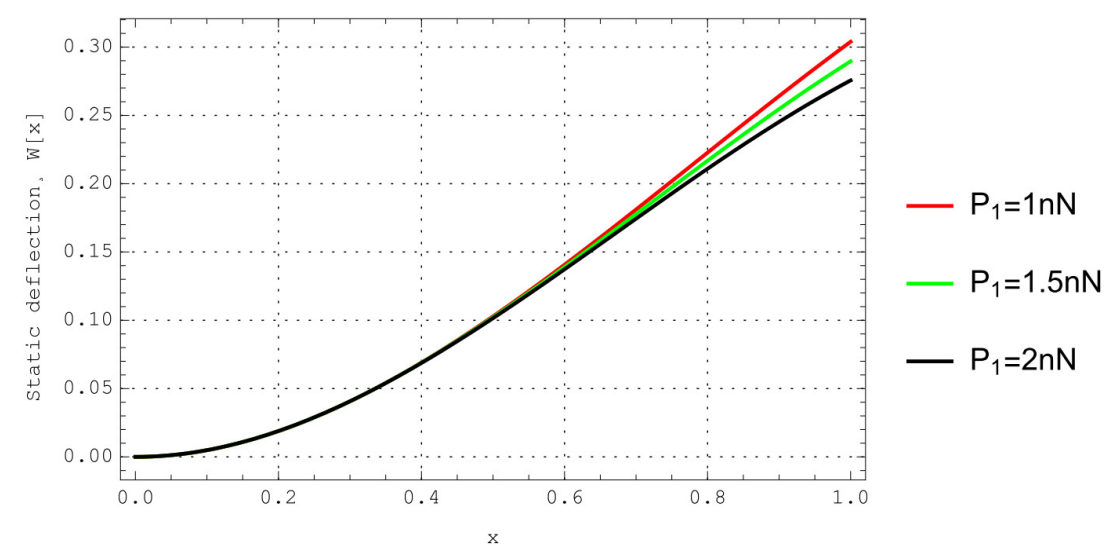

Fig. 3. Static deflection for different axial forces $\left(\mathrm{P}_{2}=1.0 \mathrm{nN}\right)$.

The effects of end forces on the slope of cantilever nanobeams are presented in Figs. 4 and 5. The figures show increase and decrease in the slope with increase in distance from fixed end which highlights the significance of end concentrated forces. So, it can be concluded that the lateral deflection is highly increased with higher values of the end lateral concentrated forces. 


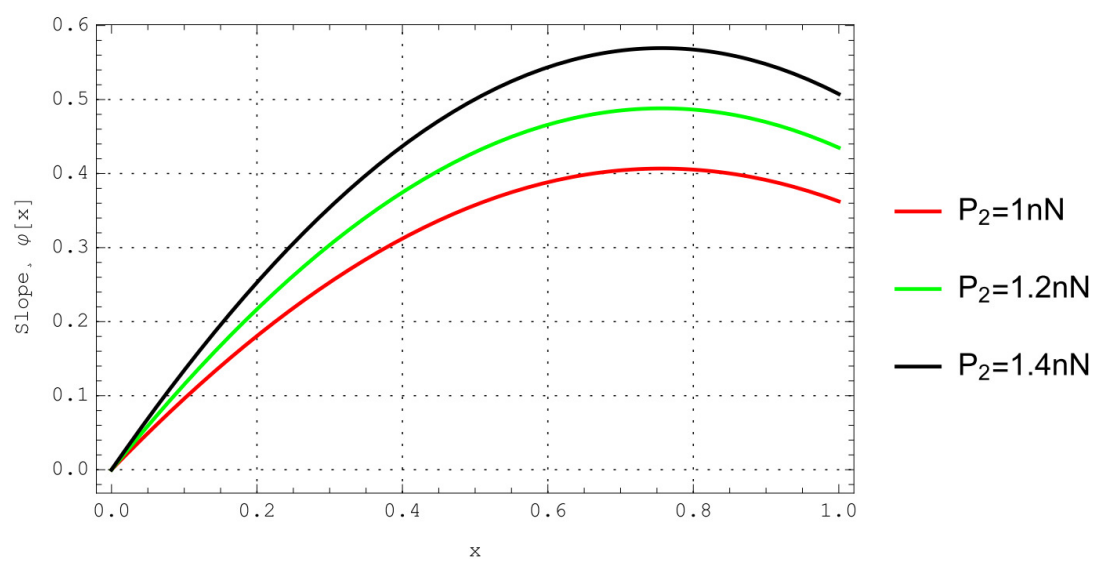

Fig. 4. Slope for different concentrated forces $\left(\mathrm{P}_{1}=1.2 \mathrm{nN}\right)$.

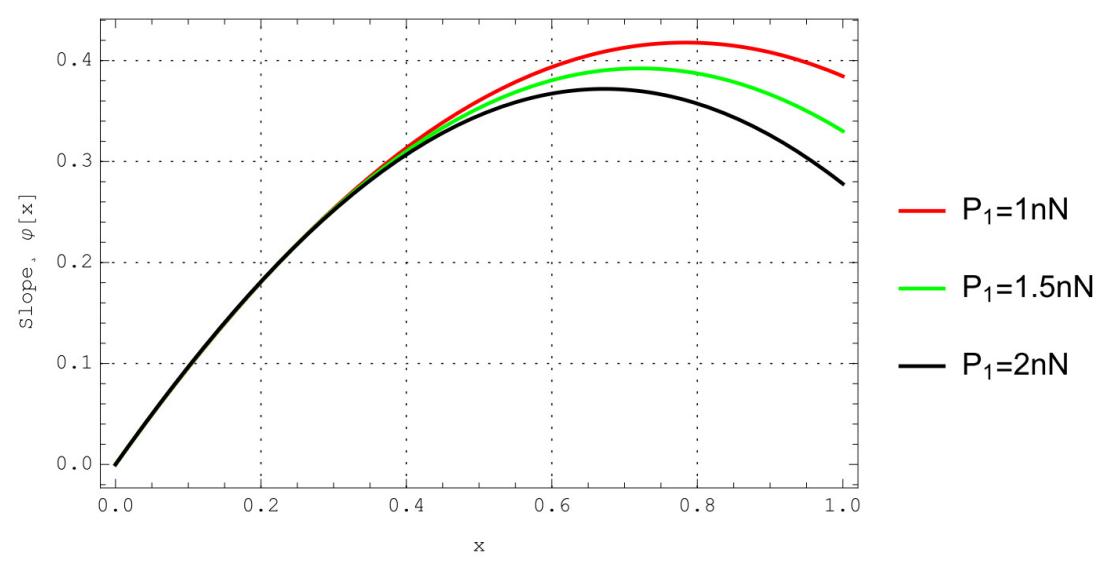

Fig. 5. Slope for different axial forces $\left(\mathrm{P}_{2}=1.0 \mathrm{nN}\right)$.

The effects of end forces on the bending of cantilever nanobeams are presented in Figs. 6 and 7. Again the influences of the axial force and the lateral force on the bending moment are quite obvious.

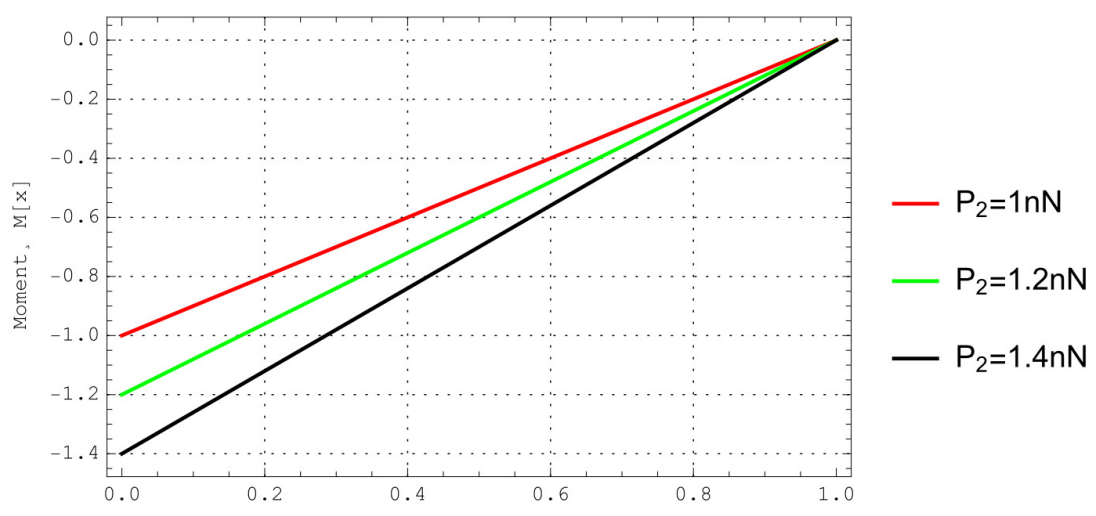

Fig. 6. Moment diagram for zero axial force $\left(\mathrm{P}_{1}=0.0 \mathrm{nN}\right)$. 


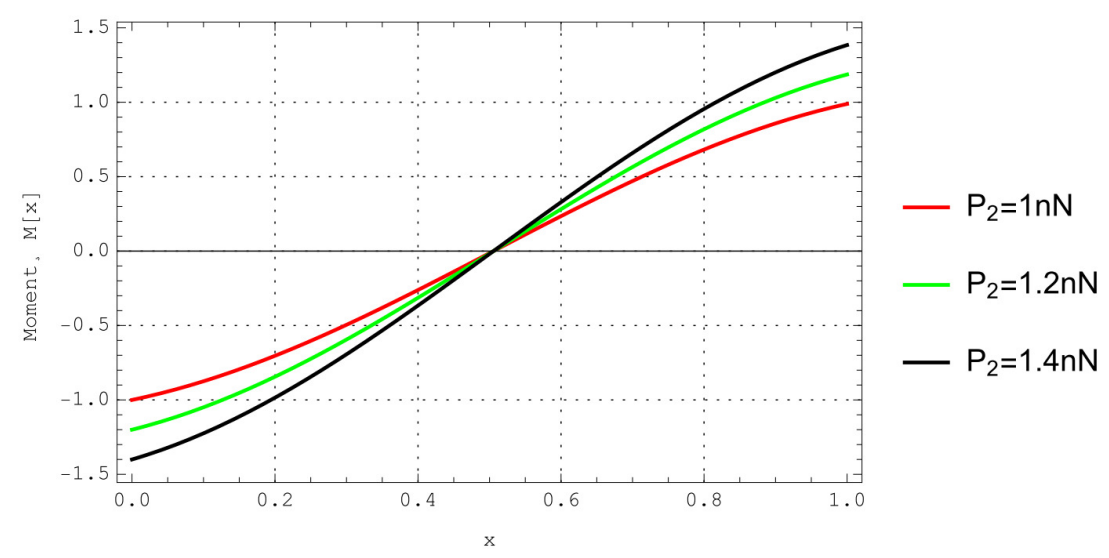

Fig. 7. Moment diagram for constant axial force $\left(\mathrm{P}_{1}=5.0 \mathrm{nN}\right)$.

\section{Conclusions}

In present work, It has been shown that the Laplace transform could be applied to solve nonlocal initial value problem that contains homogeneous linear differential equations. The single walled carbon nanotube is modeled as beam via Euler-Bernoulli theory. Nonlocal elasticity theory is used for small scale effect. One can easily transform the system of differential equations with constant coefficients into a system of (algebraic) equations with constant coefficients. Then these systems of algebraic equations can be solved and takes the inverse Laplace transform to get closed form solutions of the original equations.

\section{References}

[1] Eringen, A. C., Nonlocal polar elastic continua. International Journal of Engineering Science, 10, $1-16,1972$.

[2] Aydogdu, M., A general nonlocal beam theory: its application to nanobeam bending, buckling and vibration, Physica E 41, 1651-1655, 2009.

[3] Liu, T., Hai, M., Zhao, M., Delaminating buckling model based on nonlocal Timoshenko beam theory for microwedge indentation of a film/substrate system, Eng. Fract. Mech. 75, 4909-4919, 2008.

[4] Reddy, J.N., Nonlocal theories for bending, buckling and vibration of beams, Int. J. Eng. Sci., 45, 288-307, 2007.

[5] Narendar, S., Buckling analysis of micro-/nano-scale plates based on two variable refined plate theory incorporating nonlocal scale effects, Compos. Struct., 93, 3093-3103, 2011

[6] Pradhan, S.C., Phadikar, J.K., Nonlocal elasticity theory for vibration of nanoplates. J. Sound Vib., 325, 206-223, (2009). 
[7] Shen, L., Shen, H.S., Zhang, C.L., Nonlocal plate model for nonlinear vibration of single layer graphene sheets in thermal environments, Comput. Mater. Sci., 48, 680-685, 2010.

[8] Mercan, K., Civalek, Ö., Buckling Analysis of Silicon Carbide Nanotubes (SiCNTs). Int J Eng Appl Sci, 8(2), 101-108, 2016.

[9] Mercan, K., Demir, Ç., Akgöz, B., Civalek, Ö., Coordinate Transformation for Sector and Annular Sector Shaped Graphene Sheets on Silicone Matrix. Int J Eng Appl Sci, 7(2), 56-73, 2015.

[10] Mercan, K., Civalek, Ö., DSC method for buckling analysis of boron nitride nanotube (BNNT) surrounded by an elastic matrix. Compos Struct, 143, 300-309, 2016.

[11] Gürses, M., Akgöz, B., Civalek, Ö., Mathematical modeling of vibration problem of nano-sized annular sector plates using the nonlocal continuum theory via eight-node discrete singular convolution transformation. Appl Math Comput, 219, 3226-3240, 2012.

[12] Yayli M. Ö., Buckling Analysis of a Rotationally Restrained Single Walled Carbon Nanotube Embedded In An Elastic Medium Using Nonlocal Elasticity, Int J Eng Appl Sci, 8(2), 40-50, 2016.

[13] Yayli M. Ö., An Analytical Solution for Free Vibrations of A Cantilever Nanobeam with A Spring Mass System, Int J Eng Appl Sci, 7(4), 10-18, 2016.

[14] Civalek, Ö., Akgöz, B., Free vibration analysis of microtubules as cytoskeleton components: nonlocal Euler-Bernoulli beam modeling, Sci. Iranica Trans. B: Mech. Eng., 17, 367-375, 2010.

[15] Civalek, Ö., Demir, Ç., Bending analysis of microtubules using nonlocal Euler-Bernoulli beam theory, Appl. Math. Model., 35, 2053-2067, 2011.

[16] Wang, C.M., Kitipornchai, S., Lim, C.W., Eisenberger, M., Beam bending solutions based on nonlocal Timoshenko beam theory, J. Eng. Mech., 134, 475-481, 2008.

[17] Lu, P., Lee, H.P., Lu, C., Zhang, P.Q., Dynamic properties of flexural beams using a nonlocal elasticity model, J. Appl. Phys., 99, 73510-73518, 2006.

[18] Murmu, T., Pradhan, S.C., Small-scale effect on the vibration of nonuniform nanocantilever based on nonlocal elasticity theory, Physica E, 41, 1451-1456, 2009.

[19] Rahmani, O., Pedram, O., Analysis and modeling the size effect on vibration of functionally graded nanobeams based on nonlocal Timoshenko beam theory, Int. J. Eng. Sci, 77, 55-70, 2014.

[20] Eltaher, M.A., Emam, S.A., Mahmoud, F.F., Static and stability analysis of nonlocal functionally graded nanobeams. Compos. Struct, 96, 82-88, 2013.

[21] Thai, H.T., A nonlocal beam theory for bending, buckling, and vibration of nanobeams. Int. J. Eng. Sci., 52, 56-64, 2012.

[22] Reddy J. N., Pang, S. D., Nonlocal continuum theories of beam for the analysis of carbon nanotubes,. Journal of Applied Physics, 103, 1-16, 2008. 
[23] Setoodeh, A.R., Khosrownejad, M., Malekzadeh, P., Exact nonlocal solution for post buckling of single-walled carbon nanotubes. Physica E, 43, 1730-1737, 2011.

[24] Yayli, M.Ö., Buckling Analysis of a Rotationally Restrained Single Walled Carbon Nanotube, Acta Physica Polonica A, 127, 3, 678-683, 2015.

[25] Yayli, M.Ö., Stability analysis of gradient elastic microbeams with arbitrary boundary conditions, Journal of Mechanical Science and Technology, 29, 8, 3373-3380, 2015.

[26] Artan R., Tepe A., The initial values method for buckling of nonlocal bars with application in nanotechnology. European Journal of Mechanics-A/Solids, 27, (3), 469-477, 2008.

[27] Peddieson, J., Buchanan, G. R., McNitt, R. P., Application of nonlocal continuum models to nanotechnology. Int. J. Eng. Sci, 41, (3-5), 305-312, 2013. 